\title{
The Need for Diabetes Care Customization in the ICU at the Time of SARS-CoV-2 Outbreak
}

\author{
Sandro Gentile $\cdot$ Felice Strollo $\cdot$ Antonio Ceriello
}

Received: April 17, 2020 / Published online: April 29, 2020

(C) The Author(s) 2020

To the Editor,

In China, among SARS-CoV-2-infected people, $12 \%$ of individuals have been reported to have diabetes mellitus (DM); this figure is quite low when comparing to reported figures in Italy [1]. In fact, as of April 2, 2020, from hospital records it has been possible to collect information on 1102 of 12,550 Italian fatalities from COVID-19 [2]. The mean number of concomitant diseases was 2.7 (median $=3$ ): 31 patients $(2.8 \%)$ were free of any other disease, $243(22.1 \%)$ had only one, 263 (23.9\%) had two, and 565 (51.3\%) had at least three concomitant diseases [2]. Table 1 clearly shows that DM prevalence in deceased Italian COVID-19-positive patients was $31.5 \%$ [3]. The higher prevalence of DM in patients admitted with COVID-19 cannot be mostly a reflection of an older population known to be at higher risk for complications and mortality from COVID-19 because, while DM affects

\section{S. Gentile}

Campania University "Luigi Vanvitelli" and

Nefrocenter Research Network \& Nyx, research startup, Naples, Italy

\section{F. Strollo $(\bowtie)$}

Elle-Di and San Raffaele Research Institute, Rome, Italy

e-mail: felix.strollo@gmail.com

A. Ceriello

IRCCS MultiMedica, Milan, Italy
$17.9 \%$ of men and $16.2 \%$ of women over 80 years of age [4] against its overall $6.2 \%$ prevalence in the general population (Fig. 1), the over-80s accounted for $29.8 \%$ of deaths among COVID-19-positive patients (Table 2) against an overall figure of $11.8 \%$ (12,550 out of 106,399 documented infections in the hospital setting) [2].

When putting together such a puzzle, we clearly understand why the prognosis in COVID19-positive patients with DM can be very poor. Unfortunately, we cannot exclude that the worse prognosis in DM observed in this pandemic is not simply related to the disease itself. We must consider that in critically ill patients, treatment protocols often include extensive utilization of corticosteroids, which is known to further deteriorate infection-related hyperglycemia. It can be found in the same report from the Italian ISS (Istituto Superiore Sanità) that corticosteroids have been used in 34\% of cases [2]. This is a serious situation if not well managed, because tight glucose control improves the length of hospitalization, the disease severity, and the mortality in ICU-staying patients with DM [5]. It is well known that, when facing critically ill patients with DM requiring ICU for acute respiratory failure, doctors have to progressively customize therapeutic protocols to ever-changing individual needs, comorbidities, and any symptoms of multiple organ/ system involvement contributing to the clinical picture [6]. This particularly applies to the 
Table 1 Most common comorbidities observed in COVID-19-positive deceased patients. Source: Istituto Superiore di Sanità [3] (modified)

\begin{tabular}{lll}
\hline Disease & Number & Percentage \\
\hline Ischemic heart disease & 302 & 27.4 \\
Atrial fibrillation & 249 & 22.6 \\
Heart failure & 186 & 16.9 \\
Stroke & 127 & 11.5 \\
Hypertension & 794 & 72.1 \\
Type 2 diabetes & 347 & 31.5 \\
Dementia & 173 & 15.7 \\
COPD & 202 & 18.3 \\
Active cancer in the past 5 years & 188 & 17.1 \\
Chronic liver disease & 45 & 4.1 \\
Chronic renal failure & 259 & 23.5 \\
Number of comorbidities & & \\
0 & 31 & 2.8 \\
1 & 243 & 22.1 \\
2 & 263 & 23.9 \\
$\geq 3$ & 565 & 51.3 \\
\hline
\end{tabular}

management of hyperglycemia, and particularly to its swings [1], which can increase pro-inflammatory factors and eventually prevent patients
Table 2 Mortality rate by age class in COVID-19-positive patients. Source: Istituto Superiore di Sanità [2] (modified)

\begin{tabular}{lcc}
\hline Age groups (years) & Deceased $[\boldsymbol{n}(\%)]$ & Mortality (\%) \\
\hline $0-9$ & $0(0 \%)$ & 0 \\
$10-19$ & $0(0 \%)$ & 0 \\
$20-29$ & $6(0 \%)$ & 0.1 \\
$30-39$ & $29(0.2 \%)$ & 0.4 \\
$40-49$ & $110(0.9 \%)$ & 0.8 \\
$50-59$ & $479(3.8 \%)$ & 2.3 \\
$60-69$ & $1448(11.5 \%)$ & 8.0 \\
$70-79$ & $4196(33.4 \%)$ & 21.8 \\
$80-89$ & $5029(40.1 \%)$ & 30.9 \\
$\geq 90$ & $1251(10 \%)$ & 28.7 \\
Unknown & $2(0 \%)$ & 1.2 \\
Overall & $12,550(100 \%)$ & 11.8 \\
\hline
\end{tabular}

from benefiting of any otherwise well-managed treatment protocols. That is why, despite being fully aware that support of vital functions represents the primary goal for physicians taking care of COVID-19-infected patients, and that health professionals are overwhelmed by the dramatic situation, we strongly suggest the need in the presence of DM for continuous subcutaneous glucose monitoring systems to let them enhance the chance for a better prognosis.

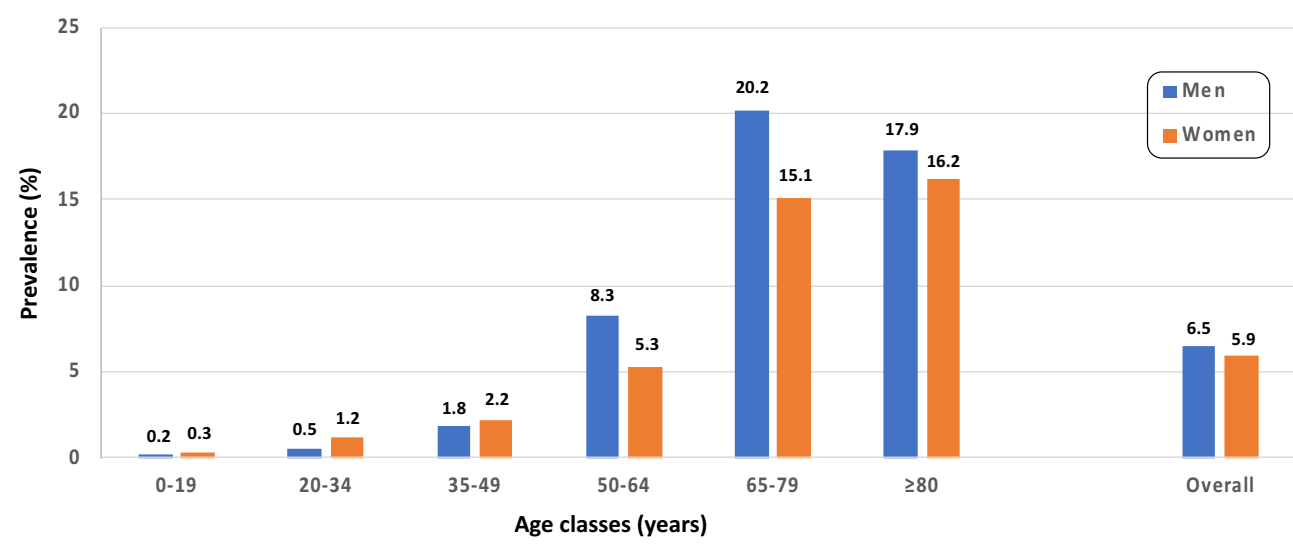

Fig. 1 DM prevalence in Italy as a function of age and gender according to the 2019 ARNO-Diabetes Report (modified) [4] 


\section{ACKNOWLEDGEMENTS}

We acknowledge the logistic support of Nefrocenter Research Network \& Nyx, research startup, Naples, Italy.

Funding. No funding or sponsorship was received for this study or publication of this article.

Authorship. All named authors meet the International Committee of Medical Journal Editors (ICMJE) criteria for authorship for this article, take responsibility for the integrity of the work as a whole, and have given their approval for this version to be published.

Disclosures. Sandro Gentile, Felice Strollo and Antonio Ceriello have nothing to disclose.

Compliance with Ethics Guidelines. This article is based on previously conducted studies and does not contain any studies with human participants or animals performed by any of the authors.

Peer Review. Please note, contrary to the journal's standard single-blind peer review process, as a commentary this article underwent review by the journal's Editor-in-Chief.

Data Availability. Data sharing is not applicable to this article as no datasets were generated or analyzed during the current study.

Open Access. This article is licensed under a Creative Commons Attribution-NonCommercial 4.0 International License, which permits any non-commercial use, sharing, adaptation, distribution and reproduction in any medium or format, as long as you give appropriate credit to the original author(s) and the source, provide a link to the Creative Commons licence, and indicate if changes were made. The images or other third party material in this article are included in the article's Creative Commons licence, unless indicated otherwise in a credit line to the material. If material is not included in the article's Creative Commons licence and your intended use is not permitted by statutory regulation or exceeds the permitted use, you will need to obtain permission directly from the copyright holder. To view a copy of this licence, visit http://creativecommons.org/licenses/by$\mathrm{nc} / 4.0 /$.

\section{REFERENCES}

1. Gentile S, Strollo F, Ceriello A. COVID-19 infection in Italian people with diabetes: lessons learned for our future (an experience to use). Diabetes Res Clin Pract. 2020;162:108137.

2. Istituto Superiore di Sanità. Characteristics of COVID19 patients dying in Italy: report based on available data on April 2nd. 2020 https://www.epicentro.iss.it/ en/coronavirus/bollettino/Report-COVID-2019_2_april_ 2020.pdf. Accessed 3 Apr 2020.

3. Istituto Superiore di Sanità. Report on COVID-19 on April 2nd. 2020 https://www.epicentro.iss.it/ coronavirus/bollettino/Infografica_2aprile\%20ITA.pdf. Accessed 3 Apr 2020.

4. Rapporto ARNO-Diabete. 2019. http://www.siditalia. it/clinica/linee-guida-societari/send/80-linee-guidadocumenti-societari/5025-rapporto-arno-diabete-2019. Accessed 3 Apr 2020.

5. Uijtendaal EV, Zwart-van Rijkom JEF, de Lange DW, Lalmohamed A, van Solinge WW, Egberts TCG. Influence of a strict glucose protocol on serum potassium and glucose concentrations and their association with mortality in intensive care patients. Crit Care. 2015;19:270.

6. Kar P, Jones KL, Horowitz M, Deane AM. Management of critically ill patients with type 2 diabetes: the need for personalised therapy. World J Diabetes. 2015;6:693-706. 